\title{
Seroprevalence of cytomegalovirus antibodies amongst normal pregnant women in Nigeria
}

This article was published in the following Dove Press journal:

International Journal of Women's Health

15 December 201।

Number of times this article has been viewed

\begin{abstract}
Akinsegun Abduljaleel
Akinbami ${ }^{1}$

Kabiru Afolarin Rabiu ${ }^{2}$

Adeniyi Abiodun Adewunmi

Kikelomo Ololade Wright ${ }^{3}$

Adedoyin Owolabi Dosunmu'

Titilope Adenike Adeyemo ${ }^{4}$

Adewumi Adediran ${ }^{4}$

Vincent Oluseye Osunkalu ${ }^{4}$

'Department of Haematology and

Blood Transfusion, ${ }^{2}$ Department

of Obstetrics and Gynaecology,

${ }^{3}$ Department of Community Medicine and Primary Health Care, College of Medicine, Lagos State University, Ikeja, ${ }^{4}$ Department of Haematology and Blood Transfusion, College of Medicine, Faculty of Clinical Sciences, University of Lagos, Idiaraba, Nigeria
\end{abstract}

Correspondence: AA Akinbami Department of Haematology and Blood Transfusion, Lagos State University, College of Medicine, Ikeja, Nigeria

Tel +234 I 8023064925

Email ajoke_clinic@yahoo.co.uk
Objective: Cytomegalovirus (CMV), a ubiquitous virus belonging to the herpes family, is known to be transmitted frequently to developing fetuses in pregnancy. In an immunocompromised state like pregnancy, primary infection through blood transfusion or reactivation of a latent CMV infection can cause severe illness. The study was carried out to determine the seroprevalence of the immunoglobulin $\mathrm{G}$ ( $\mathrm{IgG}$ ) antibody to cytomegalovirus amongst pregnant women in correlation with previous exposure to blood transfusion.

Methods: A cross sectional study was carried out amongst 179 HIV negative pregnant women attending the antenatal clinic of Lagos State University Teaching Hospital (LASUTH), Ikeja, Nigeria. Five $\mathrm{mL}$ of blood was collected and stored in a plain bottle, centrifuged on the same day and the serum stored at $-20^{\circ} \mathrm{C}$. All samples were screened for anti-CMV IgG antibodies using the enzyme linked immunosorbent assay (ELISA). Consenting participants were instructed to fill a semi-structured questionnaire to obtain demographic and other related information. Statistical analysis of the results was done using Pearson's chi squared test for analytical assessment.

Results: A total of $97.2 \%$ of the pregnant women recruited for this study were anti-CMV IgG positive. Out of the 179 recruited for the study 174 responded to the question on previous history of blood transfusion, $14.9 \%$ of the respondents (26 of 174) had a previous history of blood transfusion and all tested positive to the anti-CMVIgG antibody. However, past history of blood transfusion and educational level were found to be insignificant to the risk of acquiring CMV infection.

Conclusion: The seroprevalence of the CMV antibody amongst pregnant women in this environment is high in relation to findings in other developing countries. There is the need to assess anti-CMV immunoglobulin $\mathrm{M}$ antibodies in pregnant women, which is a determinant of active infection.

Keywords: CMV, IgG, pregnant women

\section{Introduction}

Cytomegalovirus belongs to the subfamily of herpes known as $\beta$ herpes and it is found universally in various geographic locations. CMV infection is also known to be frequently transmitted to a developing fetus. This virus remains the leading cause of congenital viral infection and a significant cause of transfusion-acquired infections in patient populations. ${ }^{1}$ Its clinical manifestations include asymptomatic forms, severe fetal damage, and death in rare cases due to spontaneous abortion.

For most healthy people who acquire CMV infection after birth or through blood transfusion, there are few symptoms and no long term sequelae. Therefore, for the vast majority of individuals, CMV infection is innocuous. ${ }^{2}$ However, CMV 
infection is important in pregnant women because of their immunocompromised state and risk of infection to the fetus whose immune system is not fully developed. Furthermore, $10 \%$ to $15 \%$ of the children who are asymptomatic at birth may develop late sequelae, especially hearing defects, after a period of months or years. ${ }^{3}$

Once a person becomes infected, the virus remains alive but usually dormant within the individual's body for life. Recurrent disease rarely occurs unless the immune system is compromised. It was reported that the risk of fetal damage is greater if the primary infection occurs during the first trimester of pregnancy. ${ }^{4-6}$ The prevalence of congenital infection ranges from $0.2 \%$ to $2.5 \%$ in different populations, ${ }^{7-13}$ with groups at greater risk including Black or Asian women, those from a low socioeconomic background, and those that are born prematurely. ${ }^{10}$

The prevalence of congenital infection varies with the prevalence of the infection in the population. ${ }^{14}$ The seroprevalence of CMV among women of childbearing age ranges from $35 \%$ to $95 \%$ in different countries. ${ }^{5,14-17}$ It is more widespread in developing countries and in areas of lower socioeconomic conditions. ${ }^{18}$

The rate of seropositivity of anti-CMV immunoglobulin $\mathrm{G}(\mathrm{IgG})$ enzyme linked immunosorbent assay (ELISA) antibodies of pregnant women in Turkey was reported to be 98.5\% ${ }^{19}$ and $84 \%$ in Spain. ${ }^{20}$ These rates are much higher than the typical European rate but similar to the rate obtained amongst Black pregnant women.

An overall rate of $87 \%$ of anti-CMV IgG ELISA antibodies in pregnant women was reported in Singapore, ${ }^{21} 100 \%$ in Thailand, ${ }^{21}$ and $93 \%$ in Iranian women of childbearing age. ${ }^{22}$

Since CMV is transmitted through blood transfusion, the strict use of blood during pregnancy and labor cannot be overemphasized as some of the pregnant women could be CMV negative.

Several studies and data support the transmission of CMV from seropositive blood donors to susceptible recipients in a variety of settings. ${ }^{23,24}$ Topin et $\mathrm{a}^{25}$ provided the first biochemical evidence for transfusion associated CMV infection. The study reported that monocyte latently infected with CMV represent the primary vector for Transfusion Associated-CMV (TA-CMV) which can be largely abrogated by transfusing at risk patients with either seronegative units or blood filtered to remove white blood cells. Lamberson et $\mathrm{al}^{26}$ also determined that a decreased incidence of transfusion associated with CMV (TA-CMV) infection occurred when only blood products that tested negative for CMV immunoglobulin M (IgM) were used.
Two hypotheses have been investigated as possible mechanisms for CMV transmission by blood. First, since CMV resides in a latent state in the infected host, it has been proposed that all CMV-seropositive blood donors can transmit the latent virus, ${ }^{27,28}$ following transfusion. In this case latent virus is reactivated and may cause active CMV infection in the recipient. Latency following a primary infection may be punctuated by periodic reactivation that gives rise to recurrent infections, and in utero transmission may occur during either primary or recurrent infections. ${ }^{29}$ Yeager and colleagues published an excellent study of TA-CMV infections in newborns to prove this fact. ${ }^{30} \mathrm{CMV}$ specific antibody of the IgM class has been recognized as a marker of active or recent primary infection with the virus. Recent reports have shown a positive correlation between post transfusion CMV infection and the receipt of blood from CMV IgM-positive donors. ${ }^{31}$

Such units of blood may be used for CMV negative pregnant women thus increasing the incidence of CMV in the population with its consequent embryopathy such as sensorineural hearing loss, chorioretinitis, mental retardation and fetal death. CMV embryopathy should be a major concern for public health irrespective of the percentage of babies affected. Therefore, the need to determine the seroprevalence of the CMV antibody in pregnant women cannot be overemphasized. This will underscore the significance of CMV screening in blood units for use in pregnancy and labor. This is necessary to avoid the transmission of CMV infected blood to women who are CMV seronegative.

\section{Subjects and method Study population}

A cross sectional study was carried out using the antenatal clinic of Lagos State University Teaching Hospital (LASUTH), Ikeja, Nigeria. The clinic registers about 150 patients daily and all consenting newly registered pregnant women were recruited for the study between July 1 and August 15, 2008. However, approval was obtained from the institution's research and ethics committee (LASUTH Health Research and Ethics Committee). Participants were instructed to fill out a structured questionnaire including demographic information and previous exposure to blood transfusion. Immunocompromised participants with a history of chronic illness, such as hepatitis, sickle cell disease, renal disorders, gestational diabetes and HIV infection were excluded. 


\section{Collection of samples}

A blood sample of $5 \mathrm{~mL}$ was collected into a sterile, nonanticoagulated bottle from each consenting participant. The sample was centrifuged and the serum separated into a sterile bottle and stored at $-20^{\circ} \mathrm{C}$.

\section{Cytomegalovirus serology}

Sera were tested for IgG CMV using the ELISA test. The CMV-specific IgG antibodies were studied by the commercial Dia.Pro Diagnostic Bioprobe CMV IgG (Milan, Italy) according to the manufacturer's instructions. All specimens were analyzed using the enzyme immunoassay test. The cutoff of IgG was set at 0.5 World Health Organization (WHO) IU/m (calibrator 2) by the kit's manufacturer.

Samples with a concentration $\geq 0.5 \mathrm{WHO} \mathrm{IU} / \mathrm{mL}$ were considered positive for CMV IgG, while samples with a concentration below the cut off were considered as negative results. The controls and the calibrators passed the validation check recommended by the manufacturer of the kit.

\section{Statistical analysis}

Statistical analysis of results was done using the statistical package for social science (SPSS 16.0, IBM, USA). The Pearson chi squared test and multiple comparisons involving post-hoc analysis such as the Bonferonni correction were used for the analytic assessment and the differences were considered to be statistically significant when the $P$-value obtained was $<0.05$.

\section{Results}

A total of 179 pregnant women were enrolled into the study. About $50.8 \%$ of them were between the ages of $25-30$ years and $0.60 \%$ were under 18 years (Table 1 ). Almost all of them $(97.20 \%)$ had anti-CMV IgG antibodies. The majority of those ( 89 of 179) who had anti-CMVIgG antibodies were between parity 1 and 4 (Table 2). It was observed that most $(70.40 \%)$ of the patients had tertiary education, followed

Table I Age in years with CMV serostatus

\begin{tabular}{lll}
\hline Age in years & anti-CMV IgG +ve & anti-CMV IgG -ve \\
\hline$<18$ & 2 & 0 \\
$19-24$ & 18 & $\mathrm{I}$ \\
$25-30$ & 89 & 2 \\
$31-35$ & 45 & $\mathrm{I}$ \\
$36-40$ & 17 & 0 \\
$4 I$ and above & 3 & $\mathrm{I}$ \\
\hline
\end{tabular}

Note: $P=0.14$.

Abbreviations: CMV, cytomegalovirus; IgG, immunoglobulin G.
Table 2 Parity with CMV seropositivity

\begin{tabular}{lll}
\hline Parity & anti-CMV IgG +ve & anti-CMV IgG -ve \\
\hline 0 & 60 & 3 \\
$1-4$ & 89 & 2 \\
5 and above & 25 & 0 \\
\hline
\end{tabular}

Note: $P=0.42$.

Abbreviations: CMV, cytomegalovirus; lgG, immunoglobulin G.

by $24.60 \%$ with secondary education. Less than $2 \%$ had no formal education (Table 3). However, levels of education did not correlate with CMV status $(P=0.14)$.

The majority (86.03\%) of the subjects were married and most of them had anti-CMV IgG antibodies, $11.17 \%$ were single and $2.7 \%$ were separated. $(P=0.11)$ (Table 4$)$.

One hundred and seventy four of the participants responded to the question on past history of transfusion while $14.94 \%$ of the 174 respondents ( 26 of 174 ) had a previous history of blood transfusion and all tested positive to the anti-CMV IgG antibody. Equally, 148 of the 174 (85.05\%) subjects had no past history of blood transfusion and 143 of the $148(96.62 \%)$ tested positive to anti-CMV IgG antibodies, but only 5 of 148 (3.37\%) tested negative to the IgG CMV $P=0.77$ (Table 5). Hence an association cannot be established between transfusion history and anti-CMV IgG positivity.

Multiple comparisons involving post hoc analysis such as the Bonferonni correction were done on level of education/ CMV serostatus, marital status/CMV serostatus, parity/CMV serostatus, and age/CMV serostatus. The tests of homogeneity of variances were $0.73,0.11,0.78$, and 0.74 respectively which were not significant, hence the use of Bonferonni rather than the Tamhane's T2 post-hoc test. None of the mean differences between the groups compared by the test was significant at 0.05 levels. Post-hoc analysis could not be performed on previous history of blood transfusion and anti-CMV seropositivity because there were fewer than three groups.

\section{Discussion}

The $97.20 \%$ seropositivity rate of IgG anti-CMV antibodies observed in this study amongst pregnant women is in keep-

Table 3 Education with CMV seropositivity

\begin{tabular}{lll}
\hline Education & anti-CMV IgG +ve & anti-CMV IgG -ve \\
\hline None & 3 & 0 \\
Primary & 5 & 1 \\
Secondary & 42 & 2 \\
Tertiary & 124 & 2 \\
\hline
\end{tabular}

Note: $P=0.14$.

Abbreviations: CMV, cytomegalovirus; lgG, immunoglobulin G. 
Table 4 Marital status with CMV seropositivity

\begin{tabular}{lll}
\hline Marital status & anti-CMV IgG +ve & anti-CMV IgG -ve \\
\hline Single & 18 & 2 \\
Married & 151 & 3 \\
Separated & 5 & 0 \\
\hline
\end{tabular}

Note: $P=0.11$

Abbreviations: CMV, cytomegalovirus; IgG, immunoglobulin G.

ing with several studies. As early as 1973, Krech reported that $\mathrm{CMV}$ antibodies are more prevalent in developing countries and areas of lower socioeconomic conditions in comparison to developed countries. ${ }^{18}$ Tookey et al, ${ }^{32}$ in a prospective study amongst pregnant women in London, found a seroprevalence as high as $88.2 \%$ in the first pregnancy of women. Their study was, however, ethnically diverse, with the highest prevalence recorded in Asian women at $88.2 \%, 77.2 \%$ in Black women, and the lowest in White women at $45.9 \%$.

The lowest percentage of $45.9 \%$ derived amongst the White pregnant women population reported by Tookey et al, is similar to the overall rate of anti-CMV IgG ELISA of $55.1 \%$ reported amongst French women, ${ }^{33}$ with $68.3 \%,{ }^{34}$ $30.4 \%,{ }^{35} 39 \%-94 \%{ }^{36}$ and $56.8 \%{ }^{37}$ in Italy, Ireland, the USA, and Australia respectively.

It is noteworthy in this study that age, parity, marital status, and educational level were not associated with the risk of CMV positivity, because they did not reach significant levels.

Blood transfusion-associated CMV infection has been proven extensively. ${ }^{9-24}$ Akinbami (2009) et al ${ }^{38}$ reported a $96 \%$ IgG anti-CMV and 19.5\% IgM anti-CMV antibodies seroprevalence amongst healthy blood donors in Lagos, Nigeria. This is quite significant because one out of every four units of blood donated is acutely infected by CMV because IgM anti-CMV antibody is a marker of active or recent primary infection with the virus. A pregnancy-related hemorrhage is still a major cause of peripartal morbidity and mortality in developing countries and blood transfusion rates may be high in these countries. In a Nigerian audit of 463 consecutive cesarean sections and blood transfusions within a period of 3 years, ${ }^{39} 25.2 \%$ cesarean section cases were transfused.

Table 5 Relationship between blood transfusion and anti-CMV IgG seropositivity

\begin{tabular}{lll}
\hline $\begin{array}{ll}\text { Past transfusion } \\
\text { history }\end{array}$ & anti-CMV IgG +ve & anti-CMV IgG -ve \\
\hline Yes & 26 & 0 \\
No & 143 & 5 \\
\hline
\end{tabular}

Note: $P=0.77$.

Abbreviations: CMV, cytomegalovirus; IgG, immunoglobulin G.
A total of $67.2 \%$ of caesarean sections of these cases were emergency. ${ }^{39}$ The rate of blood transfusion for the various indications were as follows: malpresentation (excluding breech) $66.7 \%$; placenta previa $59.1 \%$; uterine rupture $55.6 \%$; breech delivery $32 \%$; obstructed labor $28.2 \%$; previous baby $25 \%$; previous cesarean section $17.0 \%$; severe preeclampsia 11.1\%; fetal distress 10.7\%; and others, 10.3\%. Akinola et $\mathrm{al}^{40}$ also reported in a similar study a transfusion rate of $13.6 \%$ amongst cesarean section patients in southwestern Nigeria.

Despite the reported rate of lower seroprevalence of anti-CMV IgG ELISA antibodies amongst higher socioeconomic classes and in developed nations, ${ }^{18}$ lower rates of blood transfusion of $4.9 \%$ and $5.4 \%$ were reported by Dathie et $\mathrm{al}^{41}$ and Rouse et $\mathrm{al}^{42}$ respectively. In Canada ${ }^{43}$ the overall rate of blood transfusion for postpartum hemorrhage was $0.31 \%$, and $0.49 \%, 0.28 \%, 0.23 \%$ for emergency caesarean section, vaginal delivery, and elective cesarean section respectively.

In developing countries, the higher rate of anti-CMV IgG seroprevalence associated with higher requirements for blood in pregnant women poses a grave risk of CMV embryopathy. There is the need to assess anti-CMV IgM antibodies in pregnant women in these countries which is a marker of acute infection and more directly related to CMV embryopathy.

Previous history of blood transfusion and socioeconomic status were, however, found in this study not to be significant factors to CMV antibody positivity. This might be related to the high seroprevalence of anti-CMV IgG in the Nigerian population. Future studies in populations with similarly high seroprevalence may need higher recruitment numbers.

\section{Conclusion}

The seroprevalence of anti-CMV IgG is very high among pregnant women in Nigeria. Based on previous studies that showed a decrease in the incidence of CMV disease when blood was screened for CMV (IgM), the incidence of the disease can be decreased in Lagos if blood is screened for CMV. Previous blood transfusion exposure was insignificant in the risk of transmission.

\section{Limitations of this study}

1. Reliability of information on blood transfusion provided by patients and the possible reasons for finding small numbers of those who have been previously transfused. 
2. The use of IgG ELISA assay rather than $\operatorname{IgG}$ and $\mathrm{IgM}$ in determining seroprevalence of $\mathrm{CMV}$ in pregnant women.

\section{Acknowledgments}

The authors wish to acknowledge the resident doctors in the Haematology and Obstetrics/Gynaecology departments of Lagos State University Teaching Hospital who assisted greatly in the administration of questionnaires and collection of samples.

\section{Disclosure}

The authors report no conflicts of interest in this work.

\section{References}

1. Forbes BA. Acquisition of Cytomegalovirus infections: an update. Clin Microbiol Rev.1989;2(2):204-216.

2. Onarato IM, Morens DM, Martone WJ, Stansfield SK. Epidemiology of Cytomegaloviral infections; recommendations for prevention and control. Rev Infect Dis. 1985;7:479-497.

3. Stagno S, Whitley RJ. Herpes virus infections of pregnancy - part I: cytomegalovirus and Epstein-Barr virus infections. N Engl J Med. 1985; 313(20):1270-1274.

4. Stagno S, Pass RF, Cloud G, et al. Primary cytomegalovirus infection in pregnancy. Incidence, transmission to fetus, and clinical outcome. JAMA.1986;256(14):1904-1908.

5. Logan S, Tookey P, Peckham C. Antenatal and newborn screening for cytomegalovirus. Report of the working party, National Screening Committee (NSC), London, UK, Sep 2000.

6. Adler SP, Marshall B. Cytomegalovirus infections. Pediatr Rev. 2007;28(3):92-100.

7. Demmler GJ. Infectious Diseases Society of America and Centers for Disease Control: summary of a workshop on surveillance for congenital cytomegalovirus disease. Rev Infect Dis. 1991;13(2):315-329.

8. Nelson CT, Demmler GJ. Cytomegalovirus infection in the pregnant mother, fetus, and newborn infant. Clin Perinatol. 1997;24(1):151-160.

9. Gaytant MA, Steegers EAP, Semmekrot BA, Merkus MW, Galama MD. Congenital cytomegalovirus infection: review of the epidemiology and outcome. Obstet Gynecol Surv. 2002;57(4):245-256.

10. Dollard SC, Grosse SD, Ross DS. New estimates of the prevalence of neurological and sensory sequelae and mortality associated with congenital cytomegalovirus infection. Rev Med Virol. 2007;17(5): 355-363.

11. Natali A, Valcavi P, Medici MC, Dieci E, Montali S. Cytomegalovirus infection in an Italian population: antibody prevalence, virus excretion and maternal transmission. New Microbiol. 1997;20(2):123-133.

12. Barbi M, Binda S, Caroppo S, et al. Multicity Italian study of congenital cytomegalovirus infection. Pediatr Infect Dis J. 2006;25(2): $156-159$

13. Barbi M, Binda S, Primache V, Clerici D. Congenital cytomegalovirus infection in a northern Italian region. Eur J Epidemiol. 1998;14(8): 791-796.

14. Malm G, Engman ML. Congenital cytomegalovirus infections. Seminin Fetal Neonatal Med. 2007;12(3):154-159.

15. Colugnat FAB, Staras SAS, Dollard SC, Cannon MJ. Incidence of cytomegalovirus infection among the general population and pregnant women in the United States. BMC Infect Dis. 2007; 7:article 71.

16. Staras SAS, Dollard SC, Radford KW, Flanders WD, Pass RF, Cannon MJ. Seroprevalence of cytomegalovirus infection in the United States, 1988-1994. Clin Infect Dis. 2006;43(9):1143-1151.
17. Gambarotto K, Ranger-Rogez S, Aubard Y, et al. Primary cytomegalovirus infection and pregnant women: epidemiological study on 1100 women at Limoges. Pathol Biol. 1997;45(6):453-461.

18. Krech Y. Complement fixing antibodies against CMV in different parts of the world. Bull World Health Organization. 1973;49:103-106.

19. Ali S, Askin G, Hakan O, et al. CMV seroconversion in pregnancy and the incidence of congenital CMV infection. Turk $J$ Peadriatr. 2007;49:30-36.

20. Estripeant D, Moreno Y, Ahumada R, et al. Seroprevalence of Cytomegalovirus infection in peuperal women and its impact on their newborns. Ann Pediatr. 2007;66:135-139.

21. Wang A, Tank H, Tee CS, et al. Seroprevalence of Cytomegalovirus, Toxoplasmosis, and Parvovirus in pregnancy. Singapore Med J. 2000; 41(4):151-155.

22. Arabpou M, Kariyanee K, Jankhah A, et al. Human cytomegalovirus in women of child bearing age throughout Fars province-Iran: A population based cohort study. Malaysian Journal of Microbiology. 2007;3(2):23-28.

23. Chou S. Acquisition of donor strains of CMV by renal transplant recipients. N Eng J Med. 1986;314:1418-1423.

24. Bayer WL, Tegtemeier GE. The blood donor and magnitude of CMV carrier status and the prevalence of CMV antibody. Yale J Biol Med. 1976;49:5-12.

25. Topin MD, Stewart JA, Warren D, et al. Transfusion transmission of CMV confirmed by restriction endonuclease analysis. J Paediatr. 1985;107: 953-956.

26. Lamberson HV, McMillan JA, Weiner LB, et al. Prevention of transfusion associated CMV infection in neonates. $J$ Infect Dis. $1988 ; 157: 820-827$.

27. Norman DJ, Barry JM, Durr M, Wetzsteon PA. Preliminary analysis of a randomized study of buffy coat transfusions in renal transplantation. Transplant Proc. 1985; 17:2330-2332.

28. Opelz G, Terasaki PI. Dominant effect of transfusions on kidney graft survival. Transplantation. 1980;29:153-158.

29. Boppana SB, Rivera B, Fowler KB, et al. Intrauterine transmission of cytomegalovirus to infants of women with preconceptional immunity. New Engl J Med. 2001;344(18):1366-1371.

30. Yeager AS, Grumet FC, Hafleigh EB,et al. Prevention of transfusionacquired cytomegalovirus infections in newborn infants. $J$ Pediatr. 1981;98:281-287.

31. Griffiths PD, Stagno S, Pass RF, Smith RJ, Alford CA. Infection with cytomegalovirus during pregnancy: specific IgM antibodies as a marker of recent infection. J Infect Dis. 1982;145:647-653.

32. Tookey PA, Ades AE, Peckham CS. Cytomegalovirus prevalence in pregnant women: the influence of parity. Arch Dis Child. 1992;67(7): 779-783.

33. Gratacap-Cavallier B, Bosson JL, Morand P, et al. Cytomegalovirus seroprevalence in French pregnant women: parity and place of birth as major predictive factors. Eur J Epidemiol. 1998;14(2):147-152.

34. Massimo De P, Carlo A, Maria T, Alessia P, Pierangalo C. Infectious Diseases in Obstetrics and Gynaecology. 2009: Article ID 206505.

35. Knowles SJ, Grundy KC, Cafferkey MT, et al. Low cytomegalovirus seroprevalence in Irish pregnant women. Ir Med J. 2005;98: 210-212.

36. Staras SA, Dollard SC, Radford KW, et al. Seroprevalence of cytomegalovirus infection in the United States, 1988-1994. Clin Infec Dis. 2006;43:1152-1153.

37. Munro SC, Hall B, Whybin LR, et al. J Clin Microbiol. 2005;43(9): 4713-4718.

38. Akinbami AA, Akanmu AS, Adeyemo TA, et al. Seroprevalence of CMV antibodies among HIV patients and blood donors at Lagos State University Teaching Hospital. S Afr Med J. 2009;99: $528-530$.

39. Ozumbo BC, Ezegwui HU. Blood Transfusion and caesarean section in a developing country. J Obstet Gynaecol. 2006;8: 746-748. 
40. Akinola OI, Fabanwo AO, Tayo AO, et al. Evaluation of blood reservation and use for caeserian sections in a tertiary maternity unit in south western Nigeria. BMC Pregnancy Childbirth. 2010;10:57.

41. Dathie SJ, Ghosh A, Ng A, et al. Intra-operative blood loss during elective lower segment caeserian section. Br J Obstet Gynaecol. 1992;99:364-367.
42. Rouse DJ, MacPherson C, Landom M, et al. Blood transfusion and caesarian delivery. Br J Anaesth. 1998;80:195-198.

43. Balki M, Dhumme S, Kasodeker S et al. Blood transfusion for primary postpartum haemorrhage in a tertiary care hospital. J Obstet Gynaecol Can. 2008;30(11):1002-1007.

\section{Publish your work in this journal}

The International Journal of Women's Health is an international, peerreviewed open-access journal publishing original research, reports, reviews and commentaries on all aspects of women's healthcare including gynecology, obstetrics, and breast cancer. Subject areas include: Chronic conditions (migraine headaches, arthritis, osteoporosis);
Endocrine and autoimmune syndromes; Sexual and reproductive health; Psychological and psychosocial conditions. The manuscript management system is completely online and includes a very quick and fair peer-review system. Visit http://www.dovepress.com/ testimonials.php to read real quotes from published authors. 